\title{
Sistem Pendukung Keputusan Pemilihan Karyawan Terbaik Menggunakan Metode Weighted Product
}

\author{
Eka W Fridayanthie $^{1}$, Nanda Khoirurrizky ${ }^{2}$, Tri Santoso ${ }^{3}$ \\ ${ }^{1}$ UNIVERSITAS BINA SARANA INFORMATIKA \\ e-mail: eka.ewf@bsi.ac.id \\ ${ }^{2}$ STMIK NUSA MANDIRI \\ e-mail: nkhoirurrizky@gmail.com \\ ${ }^{3}$ STMIK NUSA MANDIRI \\ e-mail: tri.santoso@nusamandiri.ac.id
}

\begin{abstract}
Employees are one of the most important factors in a company, without it a company will not be able to run smoothly, but over time an employee needs encouragement in carrying out his duties. With the holding of the best employee selection on CV. Laatansa Agung Tangerang will re-ignite the enthusiasm of all employees but because the selection that has been done is chosen subjectively then the desired results are not appropriate. This is where the adoption of a decision support system can be used and one method that can be easily understood and used is a weighted product method which will calculate each alternative and raised with its weight the greater the value of an alternative, the greater the chance to be chosen. This application is in accordance with the problems experienced by $C V$. Laatansa Agung Tangerang where the results obtained will be objective because they are carried out based on the assessment that occurs in the field not based on a unilateral or subjective assessment and from here the results obtained will trigger employees of CV. Laatansa Agung Tangerang to competing to be the best employee
\end{abstract}

Keywords: Decision Support System, Weighted Product, Employee

\section{PENDAHULUAN}

Dalam sebuah perusahaan tidak terlepas dari peranan Sumber Daya Manusia (SDM) yang bekerja didalamnya. Menurut Handayani dalam Stevanus, Handayani, \& Kristiyanti, (2018), "Karyawan merupakan salah satu faktor utama dalam kelancaran, kemajuan serta keberhasilan suatu perusahaan". Kesuksesan sebuah perusahaan didukung dengan karyawan yang dapat bekerja secara optimal dan maksmal, dalam hal ini perusahaan harus mampu memotivasi atau memberi dorongan kepada karyawan agar dapat bekerja secara optimal dan selalu memberikan yang terbaik kepada perusahaan.

Selain gaji, salah satu hal yang dapat memotivasi karyawan adalah dengan pemberian bonus atau penghargaan terhadap prestasi dan hasil kerjanya. Dalam pemberian bonus ataupun penghargaan sebuah perusahaan disarankan memberikan keputusan berdasarkan karyawan terbaik dengan secara akurat dan objektif. Penilaian terhadap pemilihan karyawan terbaik tersebut yaitu dengan melihat beberapa kriteria seperti kedisiplinan, kerapihan, kecepatan, ketelitian dan keramahan. CV. Laatansa Agung Tangerang berdiri pada tahun 2007 dan sudah memiliki 3 cabang. CV. Laatansa
Agung Tangerang beroperasi dibidang digital printing dan multimedia. Selama CV. Laatansa Agung Tangerang berdiri pemilihan karyawan terbaik hanya dilakukan secara subjektif yang mana hanya akan menjadikan karyawan tidak bersemangat dalam bekerja karena penilaian tidak dilakukan secara objektif atau akurat.

Seperti pada penilitian yang telah lakukan sebelumnya oleh Yoni \& Mustafidah, (2016) Metode Weighted Product (WP) adalah salah satu metode yang digunakan untuk penyelesaian sistem pengambilan keputusan dengan mempertimbangkan kriteria dan bobot. Penelitian ini menggunakan Metode Weighted Product (WP), karena dalam pengambilan keputusan pemilihan mahasiswa lulusan terbaik tidak ada sub kriteria dan pada penilitan lainnya oleh (Hidayatulloh et al., 2018) berupa jurnal yang berjudul "Pengambilan Keputusan Penerima Beasiswa SMA Menggunakan Fuzzy Multiple Atribute Decision Making Model Weighted Product". Dalam penelitiannya kriteria yang digunakan Nilai rata-rata raport, Nilai rata-rata ijazah, Jumlah Tanggungan Orang Tua, Penghasilan Orang tua, Bidang Keahlian serta penelitian dari Syafitri, Sutradi, \& Dewi, (2019) berupa jurnal yang berjudul "Penerapan Metode Weighted Product Dalam Sistem Pendukung Keputusan Pemilihan 
Laptop Berbasis Web". Dalam penelitiannya kriteria yang digunakan Harga, Kapasistas RAM, Kapasistas Harddisk, Processor dan VGA.

Berdasarkan permasalahan diatas, penulis merancang Sistem Pendukung Keputusan (SPK) pemilihan karyawan terbaik dengan menggunakan metode weighted product artinya menurut Supriyono \& Sari, (2015) adalah "metode untuk pengambilan keputusan berdasarkan besarnya nilai preferensi yang dihitung berdasarkan pada nilai variable yang digunakan yang dipangkatkan dengan bobotnya. Semakin besar nilai preserensi suatu alternatif solusi maka alternatif solusi itu semakin disukai”

\section{METODOLOGI PENELITIAN}

\section{Tahapan Penelitian}

Tahapan penelitian dalam penelitian ini dapat digambarkan dengan flowchart dibawah ini :

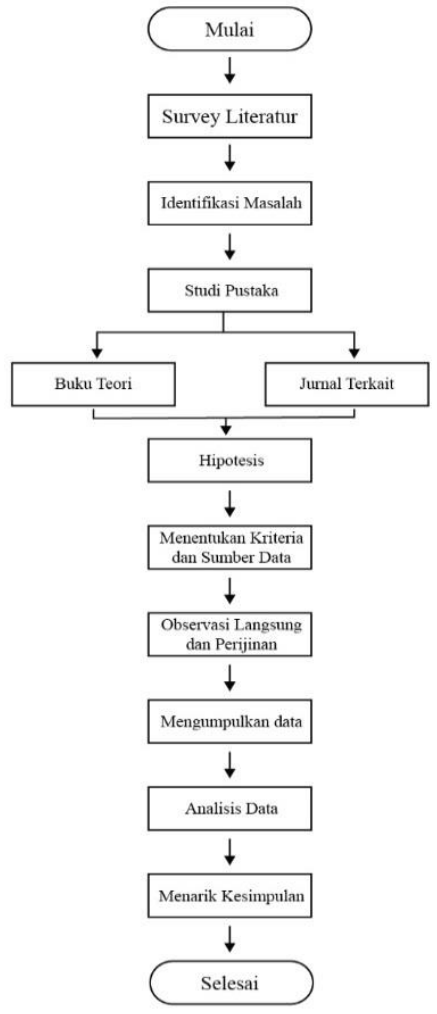

Sumber : Nanda Khoirurrizky

Gambar1. Flowchart Tahapan Penelitian

Tahapan penelitian tentang Sistem Pendukung Keputusan Pemilihan Karyawan Terbaik Menggunakan Metode Weighted Product Pada CV. Laatansa Agung Tangerang diuraikan sebagai berikut :

1. Survey Literatur

Dalam tahap awal ini penulis melakukan pengumpulan bahan literatur dari penelitian terkait.

\section{Identifikasi Masalah}

Identifikasi masalah merupakan suatu tahap dimana penulis mencari permasalahan yang akan dibahas yang mana berkaitan dengan judul yang diambil oleh penulis yaitu Sistem Pendukung Keputusan Pemilihan Karyawan Terbaik Menggunakan Metode Weighted Product Pada CV. Laatansa Agung Tangerang berdasarkan studi literatul dan dengan informasi yang telah diperoleh.

3. Studi Pustaka

Penulis mempelajari dan mengamati referensi dari buku-buku dan jurnal yang berkaitan dengan Sistem Pendukung Keputusan, Metode Weighted Product dan Manajemen Sumber Daya Manusia untuk dipergunakan sebagai kajian teori dalam penelitian 4. Hipotesa

Dalam tahap ini, penulis memiliki hipotesa awal yaitu :

a. Adakah pengaruh kedisplinan, kerapihan, keramahan, kesalahan dalam pemilihan karyawan terbaik

b. Adakah pengaruh yang lebih efektif dan efisien dengan menggunakan metode weighted product dalam penelitian pemilihan karyawan terbaik di CV. Laatansa Agung Tangerang

5. Menentukan Kriteria dan Sumber Data

Peneliti melakukan kriteria-kriteria dari Sistem Pendukung Keputusan Pemilihan Karyawan Terbaik Menggunakan Metode Weighted Product Pada CV. Laatansa Agung Tangerang diantaranya yaitu kedisplinan, kerapihan, kecepatan, ketelitian dan keramahan. Kemudian menentukan data-data yang akan dibutuhkan dalam penelitian.

6. Observasi Langsung dan Perizinan

Penulis secara langsung mengamati proses pemilihan karyawan terbaik dan meminta izin kepada pimpinan CV. Laatansa Agung Tangerang untuk melakukan penilitian.

7. Pengumpulan Data

Penulis melakukan pengumpulan data dengan memberikan kuesioner kepada pihak yang berwenang CV. Laatansa Agung Tangerang dalam proses pemilihan karyawan terbaik dan dalam hal ini pemilik selaku pemegang wewenang tertinggi pada CV. Laatansa Agung yang dijadikan responden untuk mendapatkan data yang dibutuhkan untuk membuat statistik Weighted Product

8. Analisis Data

Penulis menganalisa dan mengolah data yang didapat dari kuesioner dan dibantu menggunakan aplikasi Microsoft Excel untuk mendapatkan hasil dari perhitungan yang dilakukan

9. Menarik Kesimpulan

Penulis menarik sebuah kesimpulan berdasarkan analisis dan diperiksa kembali apakah kesimpulan yang diambil sudah sesuai dengan hipotesa, maksud dan tujuan penelitian lalu memberikan saran kepada pimpinan CV. Laatansa Agung Tangerang yang dapat digunakan sebagai sarana untuk kedepannya memperbaiki proses pemilihan karyawan terbaik.

\section{Metode Pengumpulan Data}

Metode pengumpulan data yang penulis lakukan terbagi dalam 2 cara :

1. Pengumpulan data primer

Data primer menurut Arman, Efendy, \& Sugiarto 
(2019) adalah "data yang diperoleh secara langsung dari sumbernya". Pengumpulan data primer dilakukan dengan cara melakukan observasi kegiatan pemilihan karyawan terbaik, wawancara dengan pimpinan dan pengajuan kuesioner kepada pimpinan CV. Laatansa Agung Tangerang.

2. Pengumpulan data sekunder

Data Sekunder menurut Arman et al. (2019) adalah "data yang diperoleh secara tidak langsung yang berasal dari dokumentasi yang harus dipelajari dan dari sumber lain yang berupa majalah atau buku buku" . Pengumpulan data sekunder yaitu dengan mengumpulkan dan mengidentifikasi serta mengolah data secara tertulis dari buku-buku dan jurnal yang berkaitan dengan penelitian ini

\section{Bahan Penelitian}

Bahan penelitian dari penulisan ini merupakan data karyawan CV. Laatansa Agung Tangerang dan data kuesioner yang didapat dari pimpinan CV. Laatansa Agung Tangerang.

Skala pengukuran dalam penelitian ini menggunakan skala likert yang mana menurut (Hikmawati, 2018) "Skala Likert digunakan untuk mengukur sikap, pendapat, dan persepsi seseorang atau kelompok orang tentang fenomena sosial".

Populasi dalam penelitian ini terdapat 22 orang, untuk penentuan sample penelitian digunakan non probality sampling dengan pendekatan sampling jenuh atau dapat disebut juga dengan sensus dikarenakan populasi dalam penelitian ini kurang dari 30 sample

\section{Teknik Pengumpulan Data}

\section{$1 . \quad$ Observasi}

Penulis secara langsung mengamati proses pemilihan karyawan terbaik dan meminta izin kepada pimpinan CV. Laatansa Agung Tangerang untuk melakukan penilitian

2. Wawancara

Penulis melakukan tanya jawab dan mengumpulkan informasi langsung dari pemilik dan pimpinan perusahaan CV Laatansa Agung Tangerang mengenai penilaian karyawan terbaik.

3. Studi Pustaka

Penulis melakukan studi pustaka dengan mencari referensi dari beberapa buku dan jurnal yang terkait dengan penelitian

\section{HASIL DAN PEMBAHASAN}

\section{Penentuan Nilai Bobot W (Kriteria)}

Tahap pertama yang akan dilakukan pada penggunaan metode weighted product dalam menentukan pemilihan karyawan terbaik adalah memberikan nilai pada setiap alternatif pada setiap kriteria yang sudah ditentukan dan dari masing-masing kriteria tersebut akan ditentukan bobotnya. Terdapat 5 kriteria dalam pemilihan karyawan terbaik : 1. Kedisiplinan (C1) 2 . Kerapihan (C2) 3. Kecepatan (C3) 4. Ketelitian (C4)
5. Keramahan (C5)

Tabel 1 Kriteria Kedisplinan (C1), Kerapihan (C2) Kecepatan (C3) Ketelitian (C4) Keramahan (C5)

\begin{tabular}{cc}
\hline Nilai & Bobot \\
\hline Sangat Tinggi & 5 \\
\hline Tinggi & 4 \\
\hline Cukup & 3 \\
\hline Rendah & 2 \\
\hline Sangat Rendah & 1 \\
\hline
\end{tabular}

Sumber : Nanda Khoirurrizky

Tabel 2 Nilai Prioritas bobot disetiap kriteria (W_Initj)

\begin{tabular}{cc}
\hline Kriteria & Bobot \\
\hline C1 & 30 \\
\hline C2 & 15 \\
\hline C3 & 25 \\
\hline C4 & 20 \\
\hline C5 & 10
\end{tabular}

Sumber : Nanda Khoirurrizky

Tahap selanjutnya adalah menghitung nilai perbaikan bobot $\left(\mathrm{W}_{\mathrm{j}}\right)$ berdasarkan nilai prioritas bobot disetiap

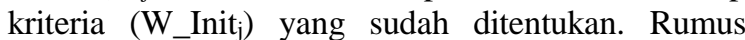
untuk menghitung nilai perbaikan bobot $\left(\mathrm{W}_{\mathrm{j}}\right)$ terdapat pada persamaan 1

$W j=\frac{W_{-} \text {Init } j}{\sum_{j=1}^{n} W_{-} \text {Init } j}$

$W 1($ Kedisiplinan $)=\frac{30}{30+15+25+20+10}=0,3$

$W 2($ Kerapihan $)=\frac{15}{30+15+25+20+10}=0,15$

$W 3($ Kecepatan $)=\frac{25}{30+15+25+20+10}=0,25$

$W 4($ Ketelitian $)=\frac{20}{30+15+25+20+10}=0,2$

$W 5($ Keramahan $)=\frac{10}{30+15+25+20+10}=0,10$

\section{Pembuatan Tabel Bobot Kriteria}

Setelah menentukan nilai dari bobot $\mathrm{W}$, tahapan selanjutnya adalah membuat tabel bobot kriteria karyawan yang terpilih menjadi karyawan terbaik. Terdapat 22 karyawan yang menjadi calon karyawan terbaik, yang mana hanya akan dipilih 1 karyawan yang terbaik. Data-data karyawan yang diperoleh seperti pada tabel 3 
Tabel 3. Data Karyawan

\begin{tabular}{|c|c|c|c|c|c|c|}
\hline \multirow{2}{*}{$\begin{array}{l}\mathrm{N} \\
\mathrm{O}\end{array}$} & \multirow{2}{*}{$\begin{array}{l}\text { NAMA } \\
\text { KARYA } \\
\text { WAN } \\
\text { (Ai) }\end{array}$} & \multicolumn{5}{|c|}{ KRITERIA } \\
\hline & & $\begin{array}{l}\mathrm{C} 1 \\
\text { :Kedis } \\
\text { iplina } \\
\mathrm{n}\end{array}$ & $\begin{array}{l}\text { C2 : } \\
\text { Kera } \\
\text { pihan }\end{array}$ & $\begin{array}{l}\text { C3 : } \\
\text { Kece } \\
\text { patan }\end{array}$ & $\begin{array}{l}\text { C4: } \\
\text { Kesal } \\
\text { ahan }\end{array}$ & $\begin{array}{l}\text { C5 } \\
\text { Kera } \\
\text { maha } \\
\mathrm{n}\end{array}$ \\
\hline 1 & $\begin{array}{l}\text { Asep } \\
\text { Nurdini }\end{array}$ & B & B & B & $\mathrm{C}$ & B \\
\hline 2 & Sarpani & A & B & B & $\mathrm{C}$ & B \\
\hline 3 & $\begin{array}{l}\text { Ridwan } \\
\text { Arifin }\end{array}$ & B & $\mathrm{C}$ & B & $\mathrm{D}$ & B \\
\hline 4 & $\begin{array}{l}\text { Rafif } \\
\text { Muhyidd } \\
\text { in }\end{array}$ & B & $\mathrm{C}$ & B & B & $\mathrm{C}$ \\
\hline 5 & $\begin{array}{l}\text { Ambar } \\
\text { Sari } \\
\text { Pamung } \\
\text { kas }\end{array}$ & B & B & $\mathrm{C}$ & A & $\mathrm{C}$ \\
\hline 6 & $\begin{array}{l}\text { Sidik } \\
\text { Purnomo }\end{array}$ & A & A & A & B & B \\
\hline 7 & $\begin{array}{l}\text { Wasyon } \\
\text { o }\end{array}$ & A & A & B & B & B \\
\hline 8 & $\begin{array}{l}\text { Delvira } \\
\text { Denanda }\end{array}$ & B & B & A & B & B \\
\hline 9 & $\begin{array}{l}\text { Rino } \\
\text { Aprianto }\end{array}$ & A & B & B & $\mathrm{C}$ & A \\
\hline $\begin{array}{l}1 \\
\mathbf{0}\end{array}$ & $\begin{array}{l}\text { Bayu } \\
\text { Saputra }\end{array}$ & B & B & B & B & A \\
\hline $\begin{array}{l}1 \\
1\end{array}$ & $\begin{array}{l}\text { Nazori } \\
\text { Malik }\end{array}$ & B & B & B & B & B \\
\hline $\begin{array}{l}1 \\
2\end{array}$ & $\begin{array}{l}\text { Siti } \\
\text { Maria } \\
\text { Ulfa }\end{array}$ & B & $\mathrm{C}$ & A & B & A \\
\hline $\begin{array}{l}1 \\
3 \\
\end{array}$ & $\begin{array}{l}\text { Kandi } \\
\text { Suhendi }\end{array}$ & A & B & A & B & $\mathrm{C}$ \\
\hline $\begin{array}{l}1 \\
4 \\
\end{array}$ & $\begin{array}{l}\text { Yuda } \\
\text { Perdana } \\
\end{array}$ & A & B & B & B & $\mathrm{C}$ \\
\hline $\begin{array}{l}1 \\
5\end{array}$ & $\begin{array}{l}\text { Angga } \\
\text { Lesmana }\end{array}$ & B & B & $\mathrm{A}$ & $\mathrm{C}$ & $\mathrm{D}$ \\
\hline $\begin{array}{l}1 \\
6\end{array}$ & $\begin{array}{l}\text { Gilang } \\
\text { Ginanjar }\end{array}$ & A & B & $\mathrm{C}$ & B & B \\
\hline $\begin{array}{l}1 \\
7\end{array}$ & Sukandi & A & B & A & A & A \\
\hline $\begin{array}{l}1 \\
8\end{array}$ & $\begin{array}{l}\text { Aceng } \\
\text { Abdulro } \\
\text { hman }\end{array}$ & A & A & A & B & B \\
\hline $\begin{array}{l}1 \\
9\end{array}$ & $\begin{array}{l}\text { Asep } \\
\text { Sobari }\end{array}$ & B & A & B & B & B \\
\hline $\begin{array}{l}2 \\
\mathbf{0}\end{array}$ & $\begin{array}{l}\text { Siti } \\
\text { Munajah }\end{array}$ & A & B & B & B & B \\
\hline $\begin{array}{l}2 \\
1 \\
\end{array}$ & $\begin{array}{l}\text { Aldo } \\
\text { Rifai }\end{array}$ & B & A & B & A & B \\
\hline $\begin{array}{l}2 \\
2\end{array}$ & $\begin{array}{l}\text { Hariswa } \\
\text { nto }\end{array}$ & B & B & A & A & $\mathrm{C}$ \\
\hline
\end{tabular}

Sumber : Khoirurrizky, Nanda

Keterangan :
A : Sangat Tinggi
$\mathrm{B}$ : Tinggi
C : Cukup
D : Rendah
E : Sangat Rendah

maka dilakukan perubahan data diskrit menjadi data kontinu seperti pada tabel 4

Tabel 4 Bobot Kriteria Karyawan

\begin{tabular}{|c|c|c|c|c|c|c|}
\hline $\mathrm{N}$ & NAMA & KRITE & & & & \\
\hline 0 & $\begin{array}{l}\text { KARYA } \\
\text { WAN }\end{array}$ & $\begin{array}{l}\mathrm{C} 1 \\
: \text { Kedis } \\
\text { iplina } \\
\mathrm{n}\end{array}$ & $\begin{array}{l}\text { C2 : } \\
\text { Kera } \\
\text { pihan }\end{array}$ & $\begin{array}{l}\text { C3 : } \\
\text { Kece } \\
\text { patan }\end{array}$ & $\begin{array}{l}\text { C4: } \\
\text { Kesal } \\
\text { ahan }\end{array}$ & $\begin{array}{l}\text { C5 : } \\
\text { Kera } \\
\text { maha } \\
\text { n }\end{array}$ \\
\hline 1 & $\begin{array}{l}\text { Asep } \\
\text { Nurdini }\end{array}$ & 4 & 4 & 4 & 3 & 4 \\
\hline 2 & Sarpani & 4 & 4 & 4 & 3 & 4 \\
\hline 3 & $\begin{array}{l}\text { Ridwan } \\
\text { Arifin }\end{array}$ & 4 & 3 & 4 & 2 & 4 \\
\hline 4 & $\begin{array}{l}\text { Rafif } \\
\text { Muhyidd } \\
\text { in }\end{array}$ & 4 & 3 & 4 & 4 & 3 \\
\hline 5 & $\begin{array}{l}\text { Ambar } \\
\text { Sari } \\
\text { Pamung } \\
\text { kas }\end{array}$ & 4 & 4 & 3 & 5 & 3 \\
\hline 6 & $\begin{array}{l}\text { Sidik } \\
\text { Purnomo }\end{array}$ & 5 & 5 & 5 & 4 & 4 \\
\hline 7 & $\begin{array}{l}\text { Wasyon } \\
\text { o }\end{array}$ & 5 & 5 & 4 & 4 & 4 \\
\hline 8 & $\begin{array}{l}\text { Delvira } \\
\text { Denanda }\end{array}$ & 4 & 4 & 5 & 4 & 4 \\
\hline 9 & $\begin{array}{l}\text { Rino } \\
\text { Aprianto }\end{array}$ & 5 & 4 & 4 & 3 & 5 \\
\hline $\begin{array}{l}1 \\
\mathbf{0}\end{array}$ & $\begin{array}{l}\text { Bayu } \\
\text { Saputra }\end{array}$ & 4 & 4 & 4 & 4 & 5 \\
\hline $\begin{array}{l}1 \\
1\end{array}$ & $\begin{array}{l}\text { Nazori } \\
\text { Malik }\end{array}$ & 4 & 4 & 4 & 4 & 4 \\
\hline $\begin{array}{l}1 \\
2\end{array}$ & $\begin{array}{l}\text { Siti } \\
\text { Maria } \\
\text { Ulfa }\end{array}$ & 4 & 3 & 5 & 4 & 5 \\
\hline $\begin{array}{l}1 \\
3\end{array}$ & $\begin{array}{l}\text { Kandi } \\
\text { Suhendi }\end{array}$ & 5 & 4 & 5 & 4 & 3 \\
\hline $\begin{array}{l}1 \\
4 \\
\end{array}$ & $\begin{array}{l}\text { Yuda } \\
\text { Perdana }\end{array}$ & 5 & 4 & 4 & 4 & 3 \\
\hline $\begin{array}{l}1 \\
5\end{array}$ & $\begin{array}{l}\text { Angga } \\
\text { Lesmana }\end{array}$ & 4 & 4 & 5 & 3 & 5 \\
\hline $\begin{array}{l}1 \\
6\end{array}$ & $\begin{array}{l}\text { Gilang } \\
\text { Ginanjar }\end{array}$ & 5 & 4 & 3 & 4 & 4 \\
\hline $\begin{array}{l}1 \\
7\end{array}$ & Sukandi & 5 & 4 & 5 & 5 & 5 \\
\hline $\begin{array}{l}1 \\
8\end{array}$ & $\begin{array}{l}\text { Aceng } \\
\text { Abdulro } \\
\text { hman }\end{array}$ & 3 & 5 & 5 & 4 & 4 \\
\hline $\begin{array}{l}1 \\
9\end{array}$ & $\begin{array}{l}\text { Asep } \\
\text { Sobari }\end{array}$ & 4 & 5 & 4 & 4 & 4 \\
\hline $\begin{array}{l}2 \\
\mathbf{0}\end{array}$ & $\begin{array}{l}\text { Siti } \\
\text { Munajah }\end{array}$ & 3 & 4 & 4 & 4 & 4 \\
\hline $\begin{array}{l}2 \\
1 \\
\end{array}$ & $\begin{array}{l}\text { Aldo } \\
\text { Rifai } \\
\end{array}$ & 4 & 5 & 4 & 5 & 4 \\
\hline $\begin{array}{l}2 \\
2\end{array}$ & $\begin{array}{l}\text { Hariswa } \\
\text { nto }\end{array}$ & 3 & 4 & 5 & 5 & 3 \\
\hline
\end{tabular}

Karena data yang diperoleh masih berupa data diskrit, 
Tabel 5 Hasil Perhitungan Vektor Vi

\begin{tabular}{lll}
\hline NO & $\begin{array}{l}\text { NAMA KARYAWAN } \\
\text { Vi) }\end{array}$ & Hasil Vi \\
\hline $\mathbf{1}$ & V1 (Asep Nurdini) & 0,043 \\
\hline $\mathbf{2}$ & V2 (Sarpani) & 0,043 \\
\hline $\mathbf{3}$ & V3 (Ridwan Arifin) & 0,038 \\
\hline $\mathbf{4}$ & V4 (Rafif Muhyiddin) & 0,042 \\
\hline $\mathbf{5}$ & V4 (Ambar Sari Pamungkas) & 0,043 \\
\hline $\mathbf{6}$ & V6 (Sidik Purnomo) & 0,050 \\
\hline $\mathbf{7}$ & V7 (Wasyono) & 0,042 \\
\hline $\mathbf{8}$ & V8 (Delvira Denanda) & 0,045 \\
\hline $\mathbf{9}$ & V9 (Rino Aprianto) & 0,049 \\
\hline $\mathbf{1 0}$ & V10 (Bayu Saputra) & 0,049 \\
\hline $\mathbf{1 1}$ & V11 (Nazori Malik) & 0,048 \\
\hline $\mathbf{1 2}$ & V12 (Siti Maria Ulfa) & 0,041 \\
\hline $\mathbf{1 3}$ & V13 (Kandi Suhendi) & 0,047 \\
\hline $\mathbf{1 4}$ & V14 (Yuda Perdana) & 0,044 \\
\hline $\mathbf{1 5}$ & V15 (Angga Lesmana) & 0,046 \\
\hline $\mathbf{1 6}$ & V16 (Gilang Ginanjar) & 0,048 \\
\hline $\mathbf{1 7}$ & V17 (Sukandi) & 0,055 \\
\hline $\mathbf{1 8}$ & V18 (Aceng Abdulrohman) & 0,045 \\
\hline $\mathbf{1 9}$ & V19 (Asep Sobari) & 0,047 \\
\hline $\mathbf{2 0}$ & V20 (Siti Munajah) & 0,042 \\
\hline $\mathbf{2 1}$ & V21 (Aldo Rifai) & 0,049 \\
\hline $\mathbf{2 2}$ & V22 (Hariswanto) & 0,045 \\
\hline $\mathbf{m b e r}:$ Nanda Khoiruitzy & \\
\hline
\end{tabular}

Sumber : Nanda Khoirurrizky

\section{Hasil Akhir Perhitungan}

Dari hasil perhitungan yang telah dilakukan, maka langkah selanjutnya adalah mengurutkan hasil vector $\mathrm{Vi}$ dari yang terbesar hingga yang terkecil dan pengurutan tersebut akan dimasukkan ke dalam tabel 6

Tabel 6 Pengurutan Hasil Vektor Vi

\begin{tabular}{lll}
\hline NO & NAMA KARYAWAN(Vi) & $\begin{array}{l}\text { Hasil } \\
\text { Vi }\end{array}$ \\
\hline $\mathbf{1}$ & V17 (Sukandi) & 0,055 \\
\hline $\mathbf{2}$ & V6 (Sidik Purnomo) & 0,050 \\
\hline $\mathbf{3}$ & V9 (Rino Aprianto) & 0,049 \\
\hline $\mathbf{4}$ & V10 (Bayu Saputra) & 0,049 \\
\hline $\mathbf{5}$ & V21 (Aldo Rifai) & 0,049 \\
\hline $\mathbf{6}$ & V11 (Nazori Malik) & 0,048 \\
\hline $\mathbf{7}$ & V16 (Gilang Ginanjar) & 0,048 \\
\hline $\mathbf{8}$ & V13 (Kandi Suhendi) & 0,047 \\
\hline $\mathbf{9}$ & V19 (Asep Sobari) & 0,047 \\
\hline $\mathbf{1 0}$ & V15 (Angga Lesmana) & 0,046
\end{tabular}

\begin{tabular}{lll}
\hline $\mathbf{1 1}$ & V8 (Delvira Denanda) & 0,045 \\
\hline $\mathbf{1 2}$ & V18 (Aceng Abdulrohman) & 0,045 \\
\hline $\mathbf{1 3}$ & V22 (Hariswanto) & 0,045 \\
\hline $\mathbf{1 4}$ & V14 (Yuda Perdana) & 0,044 \\
\hline $\mathbf{1 5}$ & V1 (Asep Nurdini) & 0,043 \\
\hline $\mathbf{1 6}$ & V2 (Sarpani) & 0,043 \\
\hline $\mathbf{1 7}$ & V4 (Ambar Sari Pamungkas) & 0,043 \\
\hline $\mathbf{1 8}$ & V4 (Rafif Muhyiddin) & 0,042 \\
\hline $\mathbf{1 9}$ & V7 (Wasyono) & 0,042 \\
\hline $\mathbf{2 0}$ & V20 (Siti Munajah) & 0,042 \\
\hline $\mathbf{2 1}$ & V12 (Siti Maria Ulfa) & 0,041 \\
\hline $\mathbf{2 2}$ & V3 (Ridwan Arifin) & 0,038
\end{tabular}

Sumber : Nanda Khoirurrizky

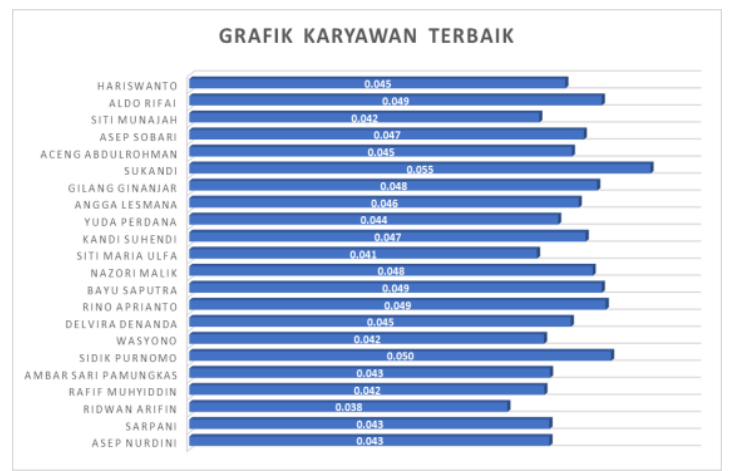

Sumber : Khoirurrizky (2019)

Gambar 2. Grafik Karyawan Terbaik

Dari hasil perhitungan yang telah dilakukan dan telah didapatkan hasil untuk pemilihan karyawaan terbaik, maka perusahaan akan memberikan apresiasi kepada Sukandi atas terpilihnya karyawan terbaik di CV. Laatansa Agung Tangerang dan berdasarkan hasil hipotesa yang telah dibuat, penggunaan metode weighted product dalam sistem pendukung keputusan berpengaruh dalam pemilihan karyawan terbaik karena data yang telah didapat memudahkan CV. Laatansa Agung dalam mengolah data untuk menentukan karyawan terbaik

\section{KESIMPULAN}

Berdasarkan penelitian yang telah penulis lakukan, dapat ditarik kesimpulan bahwa karyawan bernama Sukandi mendapat peringkat satu sebagai karyawan terbaik CV. Laatansa Agung Tangerang dengan perolehan nilai 0,05 . Dengan menggunakan metode Weighted Product, sistem pendukung keputusan pemilihan karyawan terbaik dapat terselesaikan dengan cepat, akurat dan efektif, peran pimpinan perusahaan tidak akan digantikan dengan adanya sistem pendukung keputusan pemilihan karyawan terbaik. Sistem ini hanya akan membantu pimpinan dalam memilih karyawan terbaik dengan lebih cepat, akurat dan efektif serta tanpa diunsuri subjektifitas 
yang mana akan memberikan semangat kepada semua karyawan untuk berlomba-lomba untuk menjadi karyawan terbaik.

\section{REFERENSI}

Arman, Efendy, Z., \& Sugiarto, E. (2019). SISTEM PENDUKUNG KEPUTUSAN MUTASI KARYAWAN PADA PT. SAKATO JAYA DENGAN METODE MULTI FAKTOR EVALUATION PROSES. 2(1), 9-15.

Hidayatulloh, T., Suhada, S., Nursyifa, E., Yusuf, L., Studi, P., Informasi, S., ... Informasi, S. S. (2018). Pengambilan Keputusan Penerima Beasiswa Sma Menggunakan Fuzzy Multiple Atribute Decision Making. 14(2), 247-252.

Hikmawati, F. (2018). METODOLOGI PENELITIAN (2nd ed.). Depok: PT. Raja Grafindo Persada.

Stevanus, R., Handayani, R. I., \& Kristiyanti, D. A. (2018). Laporan Akhir Penelitian - Sistem Pendukung Keputusan Pemberian Bonus Karyawan Menggunakan Metode AHP Pada
Rumah Sakit Buah Hati Ciputat. 14(2), 1. Retrieved from AHP, Expert Choice, Bonus Award

Supriyono, H., \& Sari, C. P. (2015). khazanah informatika Pemilihan Rumah Tinggal Menggunakan Metode Weighted Product. 1(1), 23-28.

Syafitri, N. A., Sutradi, \& Dewi, A. P. (2019). Penerapan Metode Weighted Product Dalam Sistem Pendukung Keputusan Pemilihan Laptop Berbasis Web. SemanTIK, 2(1), 169176.

Yoni, D., \& Mustafidah, H. (2016). Penerapan Metode WP (Weighted Product) Untuk Pemilihan Mahasiswa Lulusan Terbaik Di Fakultas Teknik Universitas Muhammadiyah Purwokerto. Juita, IV(1), 22-27.

\section{PROFIL PENULIS}

Saya Nanda Khoirurrizky, seorang profisional dalam bidang desain seperti graphic design, video grapher,drafter. 